\title{
The gist of instructional leadership practised in Swaziland primary schools
}

Hettie van der Merwe and Catherina Schenck

\begin{abstract}
A growing body of scholarship links instructional leadership to effective teaching and learning. This article looks at the 'what' of instructional leadership as practised in Swaziland primary schools. A qualitative investigation was undertaken based on individual and focus group interviews conducted at eight primary schools in the Hhohho region of Swaziland. The findings show that demonstrative leadership accompanied by collaborative support and recognition for achievement are important features of an effective instructional leadership programme. The main limitations to optimal learning are the collection of school fees during school hours and balancing English as the language of instruction with preserving the indigenous language. The findings emphasize the importance of mutual effort as the main component of effective teaching and learning.
\end{abstract}

\section{Introduction}

The closer leaders are to the core business of teaching and learning, the more likely they are to make a difference to pupils' academic performance (Robinson, 2007: 21). This statement encapsulates instructional leadership as the relationship between teacher effectiveness and learner performance and the quality of leadership provided to achieve such teaching and learning (Bush, 2013; Drysdale and Gurr, 2011; Spillane, 2006). Instructional leadership is motivated by the demand on school leaders for efficiency and accountability for classroom achievements that are mainly defined by academic outcomes in standardized tests. School leaders account for this efficiency by ensuring that the support and development of competent teachers are realized through the implementation of effective organizational processes to achieve optimal learning in the classroom.

In practice, instructional leadership is not the sole preserve of the school principal. Teachers representing different authority levels at school all perform tasks to accomplish the goal of instructional improvement (Bush, 2013). Also, as a socially distributed task, variations of context are acknowledged as an important factor in how instructional leadership is constructed and implemented (Hallinger, 2011). Part of a varied context, for example, is the distribution of instructional leadership by subject area in that the demands of the specific subject and how it is valued within the broader curriculum influence the kind of support provided to teachers (Spillane, 2006). 
Much research has been conducted on instructional leadership to capture the different nuances of responsibility-taking for teaching and learning, competencies required, the sustainment of a culture of teaching and learning, and managing optimal learning (Bisschoff and Watts, 2013; Bush, 2013; Drysdale and Gurr, 2011; Hallinger, 2003; Robinson, 2007; Spillane, 2006). In the South African context, recent research has focused on the success of instructional leadership as it pertains to different school conditions ranging from affluent to constrained circumstances (Bush and Heystek, 2006; Du Plessis, 2013; Kruger, 2003; Mestry et al., 2013; Naicker et al., 2013). The context-specific instructional leadership practices that prevail in different countries on the African continent have been less reported. Hallinger (2011) argues that more research is needed on the matching of instructional leadership strategies to context-specific conditions. He contends that 'we need to obtain better information not just about "what works" but "what works" in different settings' (Hallinger, 2011: 138). With this study's focus on the Swaziland primary school context we seek to elicit the context-specific features of instructional leadership that contribute to optimal learning in the classroom. Therefore, this article focuses on the 'what' of instructional leadership as practised in Swaziland primary schools. Our argument is that an understanding of the nature of instructional leadership practised in a context-specific African environment contributes to the global discourse on improved instructional leadership.

In this article the literature on managing teaching and learning frames our analysis of instructional leadership as practised in Swaziland primary schools. Our point of departure is a conceptualization of the concept 'instructional leadership'. We then draw on a model for instructional leadership as developed by Hallinger (2001) and the embedded situation of instructional leadership within context to serve as the theoretical framework underlying our qualitative investigation. We conclude with a discussion of the research findings that concern the main aspects pertaining to instructional leadership as practised in a specific context.

\section{The concept 'instructional leadership'}

Instructional leadership targets the school's core activities, namely teaching and learning. This concept, therefore, includes different foci representing the different nuances pertaining to giving direction to teaching and learning. Bush and Glover (2003: 10) broadly conceptualize instructional leadership as leadership that concerns teaching and learning and the behaviour of teachers in their engagement with pupils. The influence of the instructional leader is aimed at pupil learning via the teachers with the emphasis on the direction and impact of this influence, namely pupil achievement (Bush, 2011). The influence manifests itself in the provision of direction, resources and support to teachers and pupils so as to sustain a school culture of teaching and learning (Keefe and Jenkins, 2002; Kruger, 2003).

Criticism of the initial exclusive focus on teaching and teacher learning (Blasé and Blasé, 2004) resulted in a broadening of the concept to include pupil learning. This inclusion led to an alternative conceptualization of instructional leadership with the emphasis on learning, 
thus resulting in this concept also being referred to as 'leadership for learning' (Bush, 2013; Hallinger, 2011). Criticism against the perception of the school principal as the hub of expertise also brought about a shift towards expanding the concept to 'shared instructional leadership' to acknowledge the role of the other professionals shaping the instructional process (Hallinger, 2003). Teachers, for example, manage curriculum implementation in their classrooms; middle managers (heads of department) are accountable for effective teaching and learning across their subjects (learning areas); and the school principal and school management team fulfil a whole-school instructional leadership role (Gronn, 2003). Together the efforts of these different role players contribute to effective teaching in pursuit of optimal learning. Accommodating all of these explanations, the concept instructional leadership', within the context of this article, is understood to relate to what King (2002) perceives as anything that leaders from different levels do to improve the teaching and learning in their schools.

\section{A model for understanding instructional leadership}

Hallinger (2001) conceptualizes the instructional leadership construct as grounded in three dimensions: defining the school's mission, managing the instructional programme, and promoting a positive school-learning culture. An analysis of each of these dimensions provides insight into the comprehensive functioning of instructional leadership as it pertains to the Swaziland primary school context.

Defining the school's mission to represent a broad picture of the direction in which the school anticipates to move engenders a framing of school goals as the specific targets to realize (Hallinger, 2011). For Marks and Printy (2003) a clearly defined school mission creates opportunities to constantly communicate high expectations for teachers and pupils. One way of prompting such high expectations is to ensure that the instructional programme in every classroom has the same elements, following the guidelines of a standards-based education, but with competent teachers mixing their own flavour into the design (Du Plessis, 2013). These expectations relating to a learning-focused vision translating into clear learning goals create a base for all the other instructional leadership strategies and actions.

Managing the instructional programme pertains to the main tasks of coordinating the curriculum, supervising instruction, and monitoring assessment and pupil progress (Hallinger, 2001). Instructional leaders need not be curriculum experts to coordinate the curriculum, but they should have full knowledge of the centralized standards required for learning, and the assessments linked to those standards (Jenkins and Pfeifer, 2012). Monitoring pupil progress is realized through analysing and acting on pupils' achievement using formative and summative assessment, and through direct knowledge of teaching practices, learning standards and classroom dynamics (Bush, 2013). With regard to supervising instruction, the focus has changed from an 'inspector of teacher competence' to a 'facilitator of teacher development' (Marks and Printy, 2003).

One way of facilitating teacher development is through modelling. Sound teaching results when good practice is demonstrated through modelling and generalized throughout the 
school, with the incorporation of mentoring and coaching (Bush, 2013). When modelling is accompanied by professional dialogue, it engenders professional learning communities characterized by collaborative and collegial inquiry with consistent opportunities for reflection (Southworth, 2004).

Aspects that relate to promoting a positive school-learning culture that fosters and rewards learning and growth include the protection of instructional time, providing incentives for teaching and learning, promoting professional development, and maintaining constant high visibility (Hallinger, 2001; Kruger, 2003). This third dimension of the instructional leadership construct conforms to the notion that a school environment that is conducive to progress correlates with the development of high standards in pursuit of continuous improvement. In this regard Hallinger (2011) emphasizes that shared leadership is commendable in effective schools with high capacity. Schools under special measures require centralized and directive instructional leadership to create a sense of urgency for inevitable change. Part of directive leadership includes high visibility of such leaders to encourage teachers and learners to undertake a time-on-task approach based on the reality that learning, as a natural process, takes time to achieve as do all other processes in nature (Snow, 2003). High-capacity schools employ what MacGilchrist et al. (2004: 136) define as 'reflective intelligence', the constant and systematic reflection on practice that serves as a basis for shared leadership and collective and individual development. Regardless of the practice of shared leadership, the school principal remains accountable for directing and realizing the three-dimensional instructional leadership construct of aligning school structures and standards with mission statements to maintain a climate that supports teaching and learning (Jenkins and Pfeifer, 2012).

\section{Instructional leadership practised in context}

The context of a school represents opportunities and constraints that influence the type of instructional leadership practised at that school (Bloch, 2009; Hallinger, 2003; Mulford and Silins, 2009). The capacity of instructional leaders to understand the context and solve challenging situations within context determines their successes with teaching and learning (Bisschoff and Watts, 2013; Hallinger and Heck, 2010). Context-specific factors include the pupils' background, the community type, the school's organizational structure, the school culture, the teachers' experience and competence, financial resources, the school size, and labour organization arrangements (Bloch, 2009; Hallinger, 2003). The embedded situation of school-in-context brings about an interactive functioning of instructional leadership, shaping and responding to the constraints and opportunities of that context and adapting to changing conditions over time (Hallinger and Heck, 2010; Leithwood et al., 2010; Mulford and Silins, 2009; Hallinger, 2011).

Instructional leadership practice is determined by the leaders' knowledge, values and beliefs, which define both the ends towards which leaders aspire and the means by which they work to achieve these ends (Bisschoff and Watts, 2013; Hallinger, 2011; Robinson, 2007). However, due to a school's embedded situation within a specific context, every school has a mix of values that shape the behaviour of all stakeholders, including instructional 
leaders (Bisschoff and Watts, 2013; Singh and Dali, 2013). For that reason, even though instructional leadership is directed explicitly towards learning outcomes and pupil growth, the influence on pupil learning is never direct, but is mediated through school processes and conditions (Leithwood et al., 2010; Hallinger and Heck, 2010). Schools can improve their learning outcomes regardless of initial achievement levels by changing key organizational aspects such as instructional leadership and teacher capacity (Bloch, 2009; Hallinger, 2011). The interactive functioning between collaborative leadership and teacher capacity improvement, then, serves as a mutually reinforcing action with growth in one leading to positive change in the other.

All of this literature on instructional leadership practice was taken into consideration with the empirical investigation into leadership for learning as practised in the Swaziland primary school context.

\section{Research design for the empirical investigation}

To understand the 'what' of instructional leadership practised in the Swaziland primary school environment we proceeded from an interpretive paradigm using individual and focus group interviewing. Concurring with Henning et al. (2004) and Denzin and Lincoln (2011), we selected the qualitative case study genre for an in-depth understanding of the situation of those involved, as well as of the meaning they derived from their situation. Since our interest lay in process rather than outcomes, we decided that our study would entail a rich description of the context and operation of the case (Johnson and Christensen, 2004).

Swaziland has four administrative regions, namely Hhohho, in the northern part, Manzini, covering the central and western part, Shiselweni in the south and Lubombo in the eastern part of the country. Based on convenience in terms of accessibility and purposive selection (Cohen et al., 2011), participants were drawn from eight primary schools in the Hhohho region. Schools that were selected were rated high-capacity schools within a third world context based on the indicators of academic achievement and physical infrastructure. With regard to physical infrastructure, all the research sites had an adequate number of classrooms, a library, spacious playgrounds, a soccer field and two netball courts, and were fully fenced with a security guard at the school's entrance gate. Academic achievement pertained to an annual minimum pass rate of $90 \%$ in the Swaziland Primary Certificate. The eight research sites had, on average, 500 learners and 23 teachers per school. The schools were government-aided with the government paying the salaries of the staff. Additional staff were appointed with the financial support from school fees.

The participants were comprised of eight school principals and 40 teachers. The total number of participants who took part in the empirical investigation was 48 . The school principals were selected for individual interviewing as they were the executive instructional leaders accountable for teaching and learning at their schools on a daily basis. Five teachers from each school were purposefully selected for focus group interviewing. Selection of teacher participants was based on the indicators of years of teaching experience and 
representing the different levels of instructional leadership practice. We regarded five years of teaching experience at the same school as a minimum criterion to have become familiar with the school culture and to have influenced the academic performance of pupils positively as evidenced by the outcomes of the standardized annual assessment.

All the participants shared a common indicator for selection, namely that of being actively engaged in ensuring the proper functioning of the curricular programme at their respective schools. With reference to group dynamics (McMillan and Schumacher, 2006) and acquaintances limiting confidentiality (De Vos, 2005), the ethical dilemma existed of teachers possibly disparaging school leaders or being hesitant to share information in an open and honest manner. To overcome this dilemma we established a protocol by emphasizing that the focus of the research was not exclusively on leadership as practised by the school principal, but on the professional issue of instructional leadership that affects all stakeholders. Sustaining this protocol in every interview contributed to an agreement of confidentiality which resulted in open and professional participation resulting in accurately identifying and describing effective instructional leadership. We guaranteed the anonymity of participants and the confidentiality of their disclosures at all times during the research project. In line with the suggestions by Toma (2011) on rigour in the research approach, we triangulated the judgement claims of the different participants on the same questions asked. With follow-up prompts for increased clarity arranged through intensive engagement (each interview lasted at least one hour), we were able to distinguish between specific and vague statements. The follow-up prompts enabled us to determine the participants' objective opinions on good instructional leadership in pursuit of optimal learning. All 16 interviews (eight individual and eight focus group interviews) were guided by the same questions. These questions related to the context-specific understanding of the concept of instructional leadership, the influence of instructional leadership on school culture, factors impeding instructional leadership, and strategies for success.

We used qualitative content analysis to ensure that all the perspectives and issues that arose from the data were included in the report. In brief, this meant that we transcribed each interview for an immersion into the data and as an initial segmentation of the data into units of meaning (De Vos, 2005). We followed this up with open coding by reading and rereading each interview to achieve an inductive selection of codes determined at sentence level (Henning et al., 2004). After axial coding we used selective coding to ensure that themes from the labelled categories were constructed and extracted to represent the interpreted and rationalized data as research findings (Henning et al., 2004).

We referred to Guba's trustworthiness model as explained by De Vos (2005) to ensure the authenticity of our findings in terms of truth value, applicability, consistency and neutrality. On comparing the data from the 16 interviews that represented different participants from different situations and with different interpretations of reality, we found regularities and recurring patterns. This rigour produced a comprehensive and context-rich set of findings relevantly linked to theory. 


\section{Presentation and discussion of findings}

Instructional leadership in Swaziland primary schools is discussed through five themes. These themes pertain to the context-specific understanding of the concept of instructional leadership, the role to be fulfilled by the school principal, the influence of instructional leadership on school culture, factors impeding instructional leadership, and strategies for success. The themes relate to the questions posed in the interviews and concur with what was identified in the literature. Our discussion of these themes is substantiated by verbatim excerpts from the interviews. For the sake of confidentiality and authenticity, we distinguish the 40 teachers as T1, T2 and so on and the eight school principals as P1, P2 and so on.

\section{Instructional leadership understood within context}

Instructional leadership was understood as pertaining to supervision, guidance and support to teachers in the context of fostering healthy interpersonal relationships. Participant $\mathrm{P}_{5}$ rated the guiding and supervision characteristic of instructional leadership as very important so as to 'guide and supervise teachers in the teaching of the curriculum so that pupils learn the right content properly'. In order to guide teachers, healthy interpersonal relationships were seen as indispensable to be 'tuned-in to what teachers' main concerns are' (P1), so as 'to understand what teachers say even when they do not speak' ( $\mathrm{P}_{3}$ ) about their challenges with teaching. For participant P2, good interpersonal relationships were accompanied by mutual trust that was fostered when the instructional leader 'relates sincerely with teachers in teaching their classes'. This 'relating' as an empathetic understanding of what teachers' main concerns and needs are was accompanied by motivation and encouragement for the learning process. Teachers were motivated 'to continuously improve their teaching skills' while pupils were encouraged 'to increase their time spent on learning'(P6).

Mutual trust with teaching and learning relied on technical competencies practised at all levels of instructional leadership functioning. Participants emphasized that even though they performed instructional leadership tasks based on their own expertise, they relied heavily on their immediate authorities for 'direction with policy implementation' (T29). 'Demonstrative leadership' (T6) based on the instructional leader's technical know-how was, therefore, rated very important with the anticipation that 'the leader must show the way so that teaching is done according to what is expected' (T34). Another aspect that was regarded as being prominent in understanding instructional leadership within context was the attainment of parents' support for learner achievement. Parents' support for their children's academic achievement was based on emphasizing the importance of an education for possible social mobility. In this regard participant P1 emphasized that he 'mobilise[d] parents' by letting them understand the value of an education as 'the only hope... the one that will assist the learners... that will change their lives'.

Against the backdrop of shared leadership, and relying on parents' cooperation in pursuit of an education, instructional leadership was understood as providing supervision, guidance 
and support through demonstrating good practice. These initiatives were grounded soundly in healthy interpersonal relationships that encouraged teaching staff and pupils to develop a shared sense of purpose and achievement. In line with the findings of Bush and Glover (2003) and Hallinger (2003), instructional leadership within the Swaziland primary school context was understood as collaboratively giving direction to teaching with the direction of influence focused on optimal learner achievement.

\section{The role of the school principal as instructional leader}

Participants agreed that the school principal as executive instructional leader was accountable for implementing the curriculum and for enabling teachers to increase their teaching competencies to ensure that pupils learn constructively. This effort was carried out in a shared leadership arrangement as the principal works with the SMT [school management team] to provide guidelines and supervise teaching and assessment' (P6). Regardless of shared leadership, however, participants considered the school principal to be accountable for clearly spelling out the aims and objectives and sustaining uniform standards. The general feeling was that 'the school principal must not be unpredictable... we must all feel we have the same standard... the same goal!' (T19).

This shared sense of purpose was achieved through the teachers' constant alertness brought about by an arrangement with the school principal that he or she would be 'present at lessons to see how teachers carry out their teaching tasks' ( $\mathrm{T}_{3}$ ). The school principal even made unarranged classroom visits to ascertain real teaching and learning as 'it is within the principal's jurisdiction to visit classes unexpectedly' (T14). The presence of the school principal sustained the mind-set that 'school starts on time' (T9), 'morning assembly does not take longer than scheduled' (T21), and learners move quickly and orderly to their classrooms' (T8). Participants emphasized that this monitoring of teaching and learning was not interpreted as policing, but as the responsibility of the school principal as executive instructional leader to provide assistance and focus to ensure improved performance.

Monitoring teaching also included perusing teaching-related documents such as teachers' work schemes and actual learning outcomes of pupils, as was evident from pupils' exercise books and tests. It was emphasized that the monitoring of these documents did not represent a mere 'stamp of the teachers' prep-books and learners'tests', (T30) but involved cognition of what was learned in the classroom in order to arrange for support where needed. A participant motivated his monitoring actions as follows: 'I have to see for myself that what is recorded happens in the classroom... to what extent does it happen' (P1). An aspect relating to the monitoring of teaching and learning was that the school principal should be held accountable for sufficient teaching materials to be delivered in a timely manner. A participant emphasized that 'the basic teaching materials like books and stationery should be at the school before schools open... the principal should make sure of that' (T37).

School principals as instructional leaders were accountable for constructive discipline based on personal conduct of exemplary self-control. Participant $\mathrm{T}_{5}$ explained as follows: 'The 
principal should set the example by being punctual, dress properly, be polite to everyone... teachers will feel compelled to do likewise'. Being exemplary included that school principals taught some classes to motivate teachers to persevere with their own teaching. When school principals performed teaching tasks, they contributed to improved school and classroom discipline through their personal encounters with discipline-related challenges in the classroom. In this regard participant $\mathrm{P}_{3}$ stated: 'Look at my cuffs, I am from class... helps me understand discipline challenges first hand'. Related to constructive discipline was the need for school principals as instructional leaders to acknowledge good work by teachers to serve as intrinsic motivation for sustained commitment. These incentives were in the form of anything ranging from praise to small gifts or certain privileges because, 'as teachers we don't expect much, but anything to show that we are appreciated, even a pat on the shoulder would do' (T33).

An important facet of instructional leadership was the need for school principals as executive leaders to protect teachers against unreasonable actions by parents. Participants emphasized that school principals avoided unnecessary confrontation between teachers and parents who 'expect too much from teachers' (T31). By addressing parents' concerns, the school principal protected undisturbed teaching time and the possible harm to teacher-pupil relationships by parents who 'don't tolerate a simple mistake from teachers' (T14).

In line with the findings of Jenkins and Pfeifer (2012), it was clear that within the Swaziland primary school context the school principal remained accountable for what happened in the classroom. This accountability was realized through the communication of clear teaching goals and the facilitation of consistent teaching which, in a third world context, relied on a combination of shared and directive instructional leadership. Acknowledging good work and being actively part of teaching enhanced a mutual sense of belonging which correlated with Southworth's (2004) findings on collaborative and collegial effort for improved performance. Finally, and in line with the work of Hallinger (2011) on valuesdriven leadership, a practice-what-one-preaches approach was considered as most crucial to the encompassing instructional leadership role of the school principal.

\section{The influence of instructional leadership on school culture}

There was agreement by participants that developing and sustaining a culture of teaching and learning is crucial to instructional leadership so as to improve the teaching morale of each individual teacher. In this regard participant P2 stated: 'Keep the people happy and motivated and you'll be happy about the work they do for the school'. A factor identified as crucial to constructive teaching and learning was the value placed on time-on-task. Participants emphasized the fostering of respect for teaching time. When teachers and pupils respect the time allocated to teaching and learning, which is, according to one participant, 'approximately six hours including break', teachers should have 'adequate time for teaching and pupils enough time to learn' $(\mathrm{P} 7)$. 
Inherent in the way things were done at the different research sites was the fostering of collaboration based on the support of the instructional leader and fellow colleagues to realize shared goals. A participant explained as follows: 'What makes us work effectively is that we are comfortable and know that our leaders and colleagues are there to support us... there is no one carrying a whip behind us' (T17). In a context of mutual cognition of purpose, impromptu class visits by the instructional leader were then valued as co-ownership of the teaching task. The result was that teaching staff consistently ensured that teaching and marking was in order, 'not out of fear, but because he [instructional leader] shows responsibility too' (T16). This collaborative ownership of teaching and learning engendered a team effort because teachers were aware that 'once one disengages, the efforts of the others fail' (T18).

The influence of instructional leadership on school culture was evident in the fostering of a mutual sense of purpose in which each individual teacher and school manager took ownership for realizing shared objectives focused on learning outcomes. Concurring with Kruger (2003) and Du Plessis (2013), instruction time was respected as indispensably part of a culture of teaching for optimal learning.

\section{Factors impeding instructional leadership}

It was clear from the interviews that the main factors impeding instructional leadership related to cases of ineffective and unprofessional conduct and to disputes about the language of instruction. In this regard, time wasters were identified as a common detriment to teaching and learning. A constant reminder to staff to adhere to curricular activities as indicated on the school timetable and to stick to timeframes in meetings served to counteract time wasters. Meetings were rated unconstructive if not preceded by an agenda distributed in time to arrange for prepared attendance. In this regard, participant P1 emphasized that policy at his school demanded that 'the agenda for a meeting must be distributed to all attendees a day before the meeting takes place'. Due to the value of meetings that were focused on staff development but that could be lengthy, these meetings were scheduled towards the end of the school day because 'staff like to spend time after the meeting to discuss items on the agenda informally' (P1).

A strong feeling prevailed among participants about the relation between effective instructional leadership and teachers acting professionally and responsibly despite their personal differences. It was important to 'play the ball, not the person' ( $\mathrm{P}_{7}$ ) by tolerating differences while criticizing a lack of dedicated teaching. In this regard participant P8 explained: 'We may differ in our opinions on how we teach, but we must agree on persistent teaching'. In relation to professional conduct, decisions affecting teachers' work allocation had to be taken democratically. Participants emphasized the hampering effect of undemocratic decision-making such as where 'a teacher is allocated to a class and out of the blue is transferred to another within the same year and no explanation is given' (T14). In this regard the Swazi expression 'umjaj'akaphikiswa' (T11) (the judge's decision is final) hampered effective teaching because 'as professionals we need to be involved in decisions taken, especially when they [decisions] involve our teaching' (T11). Related to democratic 
decision-making was the need to involve teachers with expert knowledge on school readiness in decisions on pupil admissions. Admitting pupils who were not school-ready impeded the instructional programme 'as these pupils don't cope in the classroom' (T2). Further, negating teachers' decisions with regard to pupil admissions often caused school capacity to be exceeded. The result was then large class sizes' (T32), 'poor class management' (T26) and 'insufficient resources' (T21), which all impacted negatively on teaching and learning.

The method of collecting school fees also impeded the instructional programme. Although 'the money paid by parents cater[s] for the needs of the school' (P8), the manner in which these fees was collected hampered teachers' efforts with revision for the examinations. As a last resort to balance the school budget, pupils were sent home by the end of the school term to arrange for the collection of outstanding school fees. Apart from the negative emotional effect on the child who was sent home, teachers' instructional time to assist pupils with revision for the term-end examinations was infringed. Participant T18 explained that: 'when you have some of the class sent home at a time you are preparing for exams, you get frustrated because you know how crucial that time is for revision... a last effort to understand important content'. A final factor hindering instructional leadership and effective teaching and learning was the dispute about the language of instruction. Even though both English and Swazi were recognized as official languages, English had become the main language of instruction enabling access to a rich selection of national and international resources, with world citizen mobility possibilities for pupils. The demand to use Swazi as the language of instruction to safeguard its heritage had a negative influence on pupils' competence in English and their learning in general as 'most materials are written in English' (T34). The result was that 'children can no longer express themselves properly [due to] the argument for SiSwati instruction'. Participants emphasized that the language debate 'is a political argument' (T35) that is not in the pupils' best interest.

With reference to the work by Hallinger (2001) on conceptualizing instructional leadership, it was clear that the factors impeding teaching and learning related to sustaining a dedicated focus on instruction time and on what is best for the child. Shared decision-making to reflect the input of teachers on pupil admissions and language of instruction was considered crucial for optimal learning as the main goal of instructional leadership.

\section{Strategies for successful learning}

A number of instructional leadership strategies were raised as being conducive to positive pupil achievement. A first strategy entailed making the learning event interesting by using tangible teaching material because 'a clean, bare classroom does not grab the learners' imagination' ( $\left.\mathrm{P}_{5}\right)$. Participants agreed that successful learning implied different teaching methods to accommodate 'visual, auditory and tactile learners' ( $\left.\mathrm{T}_{4}\right)$ to ensure that head knowledge becomes heart knowledge for every learner' (T4). Stakeholder responsibility as a learning strategy was promoted through 'open house' where teachers, parents and pupils constructively met to discuss learning. Participant $\mathrm{P}_{3}$ explained the value of these events, namely that 'when teachers and parents meet over the child's work, the work speaks 
for itself', reflecting either successes or shortcomings to be addressed. These open house days, one in each semester, which could be daunting if the teacher needs to do more or the child or the parent... no one wants to be put in the spotlight' (T20), represented a mutual effort focused on pupil achievement.

The strategy of reward for conscientious learning manifested in teachers using encouraging remarks and praise such as awarding credits, merits and stars because 'learners should consistently be encouraged to do exceptionally' (T40). Within the context of the primary school environment and by teaching the lower grades, participant $\mathrm{T}_{4}$ explained that her way of encouragement was to 'hug my pupils and tell them: "I'm proud of you". Related to encouraging learning was encouraging teaching through team-building initiatives that fostered a sense of shared purpose and receptiveness for improved performance. Participant $\mathrm{P}_{4}$ explained that if you show appreciation for your teachers for the work they do, it becomes easy to correct them when they miss the mark'. Being familiar with teachers' personal circumstances enabled counteracting measures when a teacher was physically or emotionally not well and effective teaching and learning was being hampered. Participant P8 explained that 'to know what's going on with teacher so and so that day, enable me [instructional leader] to know that nothing is happening in grade three today... find a way to relieve that teacher' in order for uninterrupted teaching and learning to proceed.

The strategy of safeguarding instructional time as time that is exclusively spent on teaching and learning was accompanied by conscientious prioritizing to ensure that 'staff use the God-given asset of time appropriately' (P1). Part of the time-on-task strategy was to give pupils constructive assignments to do in class and at home. The approach was to 'even give holiday activities' (T35) because pupils gain valuable knowledge and skills by finding solutions from resources outside the classroom and the normal homework hours. Related to focused prioritizing was the strategy of briefing the next year's teacher on the circumstances of each individual pupil. The briefing exercise ensured continuity with teaching and learning as explained by participant T2: 'At the beginning of the year I make sure I hand over my pupils to the next teacher by discussing special challenges and strengths where I feel necessary. I also follow up on their progress as if they were my own children'.

A final strategy for successful learning involved staff development and employing staff according to each one's individual strength. Personal strength related to subject or grade specialization representing 'people who are foundation layers, the ones with special abilities for mid classes and then those who are finishers in the higher and exit grades' (T30). Two aspects pertaining to staff development related to the mentoring of new teachers - 'whether these newcomers are fresh from college or from other schools' (T17) - and subject panel support for teaching. Subject panels consisted of heads of department with senior and expert teachers of the specific subjects. These subject panels were assigned the responsibility of monitoring and assisting with the teaching of their subjects through modelling good practice and arranging workshops on important aspects of curriculum facilitation. Based on a shared 
instructional leadership approach, 'when a teacher encounters problems in teaching a certain concept, the subject panel is there to provide assistance... the important thing is to learn from one another' $(\mathrm{P} 7)$.

It was clear that the strategies employed to ensure teaching and learning pertained to promoting a positive school-learning culture. Essential strategies represented constant motivation and assistance in pursuit of good performance, a shared sense of prioritizing time, and a constructive utilization of teacher skills. In line with the findings of Bush (2013), Marks and Printy (2003) and Southworth (2004), the professional development of teachers was based on collaborative support from experts on subject-related instruction and knowledge of the individual child. Comprehensive teacher support, accompanied by timefocused functioning and recognition for dedicated input resulted in effective teaching and learning at the research sites as reflected in an annual minimum pass rate of $90 \%$ in standardized assessments.

\section{Conclusion}

The practice of instructional leadership within the Swaziland primary school context concurs with the findings of Bush (2013) and Hallinger (2003) that collaborative effort based on shared leadership and healthy interpersonal relationships results in optimal pupil learning. Instructional leadership as practised in Swaziland also concurs with the findings of Jenkins and Pfeifer (2012), namely that school principals as executive leaders remain accountable for the collaborative good functioning of teaching and learning. Within the Swaziland context this accountability implied a mixture of shared and directive leadership for learning based on the school principal's modelling of good technical conduct.

Based on Hallinger's (2001) three-dimensional construct, the 'what' of instructional leadership within the Swaziland primary school context pertains to demonstrative leadership to facilitate a shared vision with clear teaching and learning goals pursued in a directive way. Key factors of the instructional leadership programme include collaborative support through subject panels, recognition for achievement, the pursuit of healthy interpersonal relationships, and a non-negotiable respect for instruction time. Challenges with instruction represent a consistent effort to ensure that professional conduct prevails when differences of opinion on teaching and learning arise. Challenges also pertain to counteracting the manner of collecting outstanding school fees that impedes valuable instruction time. Balancing the advantages of English as language of instruction with conserving Swazi as indigenous language is a conundrum. Strategies considered as crucial to the practice of instructional leadership pertain to utilizing staff expertise effectively and considering staff input on matters that relate to teaching and the admission of learners. The strategy of arranging for continuity with regard to sharing knowledge on pupils' background information from one year to the next promotes optimal growth.

The findings contribute to the practice of instructional leadership in the sense of reascertaining what the important features are to consider for successful teaching and learning. Countering the stumbling block of an ineffective manner of collecting much-needed 
school fees is important. It is therefore suggested that further research be conducted on ways to collect school fees effectively within context so that teaching and learning are not infringed. Pupils need to be optimally prepared for world citizenship. For that reason research needs to be conducted on ways to balance English as language of teaching and learning with preserving Swazi as the indigenous language. Finally, and in concurrence with Hallinger (2011) on studying different settings, it is suggested that research be conducted in other African countries to compare findings on the 'what' in different contexts in pursuit of global improved instructional leadership.

\section{Funding}

This research received no specific grant from any funding agency in the public, commercial, or not-for-profit sectors. 


\section{References}

Bisschoff T and Watts P (2013) Leadership for learning: A case of leadership development through challenging situations. Education as Change 17(S1): 21-31.

Blair M (2002) Effective school leadership: The multi-ethnic context. British Journal of Sociology of Education 23(2): 179-191.

Blasé J and Blasé J (2004) Handbook Of Instructional Leadership: How Successful Principals Promote Teaching and Learning. Thousand Oaks, CA: Corwin Press.

Bloch G (2009) The Toxic Mix. What's Wrong with South Africa's Schools and How to Fix it. Cape Town: Tafelberg.

Bush T (2011) Theories of Educational Leadership and Management. $4^{\text {th }}$ ed. London: Sage.

Bush $T$ (2013) Instructional leadership and leadership for learning: Global and South African perspectives. Education as Change 17(S1): 5-20.

Bush T and Glover D (2003) School Leadership: Concepts and Evidence. Nottingham: National College for School Leadership.

Bush T and Heystek J (2006) School leadership and management in South Africa: Principals' perceptions. International Studies in Educational Administration 34(3): $63-76$.

Cohen L, Manion L and Morrison K (2011) Research Methods in Education. $7^{\text {th }}$ ed. London: Routledge Falmer.

Denzin NK and Lincoln YS (eds) (2011) The SAGE Handbook of Qualitative Research. $4^{\text {th }}$ ed. Thousand Oaks, Calif: SAGE Publications, Inc.

De Vos AS (2005) Qualitative data analysis and interpretation. In: De Vos AS (ed.) Research at Grass Roots: A Primer for the Caring Professions. $3^{\text {rd }}$ ed. Pretoria: Van Schaik, pp.333-348.

Drysdale L and Gurr D (2011) Theory and practice of successful school leadership in Australia. School Leadership and Management 31(4): 355-368.

Du Plessis P (2013) The principal as instructional leader: Guiding schools to improve instruction. Education as Change 17(S1): 79-92.

Gronn P (2003) The New Workof Educational Leaders: Changing Leadership Practice in an Era of School Reform. London: Sage Publications.

Hallinger P (2001) A review of two decades of research on the principalship using the Principal Instructional Management Rating Scale. In: Annual Meeting of the American Educational Research Association, Seattle, Washington, 10-14 April.

Hallinger P (2003) Leading educational change: Reflections on the practice of instructional and transformational leadership. Cambridge Journal of Education 33(3): 329-351.

Hallinger P (2011) Leadership for learning: Lessons from 40 years of empirical research. Journal of Educational Administration 49(2): 125-142.

Hallinger P and Heck RH (2010) Collaborative leadership and school improvement: Understanding the impact on school capacity and student learning. School Leadership and Management 30(2): 95-110.

Henning E, Van Rensburg W and Smit B (2004) Finding Your Way in Qualitative Research. Pretoria: Van Schaik. 
Jenkins J and Pfeifer RS (2012) The principal as curriculum leader. Principal Leadership 12(5): 30-34. Johnson B and Christensen L (2004) Educational Research: Quantitative, Qualitative, and Mixed Approaches. $2^{\text {nd }}$ ed. Boston, MA: Pearson.

Keefe JW and Jenkins JM (2002) Personalized instruction. Phi Delta Kappan 83(6): 440456. King D (2002) The changing shape of leadership. Educational Leadership 59(8): 61-63.

Kruger A (2003) Instructional leadership: The impact on the culture of teaching and learning in two effective secondary schools. South African Journal of Education 23(3): 206211.

Leithwood K, Anderson S, Mascall B and Strauss T (2010) School leaders' influences on student learning: The four paths. In: Bush T, Bell L and Middlewood D (eds) The Principles Of Educational Leadership and Management. London: Sage Publications, pp.13-30.

MacGilchrist B, Myers K and Reed J (2004) The Intelligent School. $2^{\text {nd }}$ ed. London: SAGE.

McMillan JH and Schumacher S (2006) Research in Education. Evidence-based Inquiry. $6^{\text {th }}$ ed. Boston US: Pearson.

Marks H and Printy S (2003). Principal leadership and school performance: An integration of transformation and instructional leadership. Educational Administration Quarterly 39(3): 370-397.

Mestry R, Moonsammy-Koopasammy I and Schmidt M (2013) The instructional leadership role of primary school principals. Education as Change 17(S1): 49-64.

Mulford B and Silins H (2009) Revised models and conceptualization of successful school principalship in Tasmania. In: Mulford B and Edmunds B (eds) Successful School Principalship in Tasmania. Launceston: Faculty of Education, University of Tasmania, pp.17-38.

Naicker I, Chikoko V and Mthiyane SE (2013) Instructional leadership practices in challenging school contexts. Education as Change 17(S1): 137-150.

Robinson V (2007) School Leadership and Student Outcomes: Identifying What Works and Why? Melbourne: Australian Council of Leaders.

Singh P and Dali CM (2013) The value of empathy as an instructional leadership competency for school principals. Education as Change 17(S1): 65-78.

Snow AL (2003) Practical Advice for Principals. Lanham, MD: Scarecrow Press.

Southworth G (2004) Learning-centred leadership. In: Davies B (ed) The Essentials Of School Leadership. London: Paul Chapman Publishing, pp.75-92.

Spillane JP (2006) Distributed Leadership. San Francisco: Jossey-Bass.

Toma JD (2011) Approaching rigour in applied qualitative research. In: Conrad CF and Serlin RC (eds) The SAGE Handbook for Research in Education. Pursuing Ideas as the Keystone of Exemplary Inquiry. $2^{\text {nd }}$ ed. Los Angeles: SAGE, pp.263-280. 